\title{
Towards a science of rabies elimination
}

\author{
Jakob Zinsstag
}

\begin{abstract}
Wenwu Yin and co-workers conducted a systematic review on challenges and needs to eliminate rabies in China (Yin et al., 2013 in this journal). Their analysis shows that there is considerable overrepresentation of laboratory and basic epidemiology research. On the other hand, information on effective control activities and policies are nearly absent. Currently we know enough to control and eliminate dog rabies effectively. Continuing basic research while not engaging in the control of rabies appears almost cynical. Why is it not attractive to do research on effective control and elimination? Let us move now from the biological understanding to the science of rabies elimination.
\end{abstract}

Keywords: Rabies, Dog, China, Control, Elimination

\section{Multilingual abstracts}

Please see Additional file 1 for translations of the abstract into the six official working languages of the United Nations.

\section{Background}

Scientific inquiry generates new knowledge and establishes an evidence-base on which modern society relays for informed decisions and, ultimately, action [1]. Currently there is an exponential growth of accumulated knowledge, making it harder and harder to reach the edge of understanding, also coined "the burden of knowledge" (Benjamin Jones, Northwestern University, Chicago IL, USA, unpublished). One would argue that with so much accumulated knowledge and an ever deeper understanding, its translation into action and improvement of human health and wellbeing would be accelerated. However, there is a huge, and perhaps widening gap between knowledge and action, or rather the lack thereof. This issue is convincingly documented by Wenwu Yin and co-workers, who conducted a systematic review and analysed the scientific literature on rabies in the People's Republic of China to examine challenges and needs to eliminate rabies in the country ([2] in this journal).

\section{Main text}

In the case of dog rabies, basically all is known about the biology of rabies to effectively implement elimination [3]. To wit, highly efficacious vaccines are available for dogs.

\footnotetext{
Correspondence: jakob.zinsstag@unibas.ch

Swiss Tropical and Public Health Institute, Associated Institute to the University of Basel, PO Box CH-4002, Basel, Switzerland
}

Dog rabies has been eliminated in large parts of the industrialized countries in Europe and North America. In the last decades, a concerted effort of South and Central American countries has strongly reduced dog rabies close to elimination [4]. Dog rabies persists and has even reemerged in Asia and Africa where still more than 60'000 people die annually from this preventable disease. The largest part of the burden is borne by India and South East Asian countries followed by China (Figure 1) [5]. Using dog-human transmission models, it has been shown that dog mass vaccination leads to rabies elimination and is more cost-effective than exclusive implementation of human post exposure prophylaxis [6]. The basic reproductive ratio of dog rabies is less than 2, making it an ideal candidate for worldwide elimination [7], a goal that is pursued by the partners for rabies prevention www.rabiesalliance.org.

However, why is there no or insufficiently effective action to control and eliminate dog rabies? Yin's paper, based on a systematic analysis of published literature and official documents shows that there is considerable overrepresentation of laboratory investigations or pathogenassociated and basic epidemiology research. On the other hand, information on effective control activities and policies are nearly absent. There is a lack of awareness in the general population about rabies and how to handle exposure to rabies suspected dog bites. Albeit some progress, there is still a lack of standardization of post exposure treatment in China, making it the worlds largest market for human rabies vaccination with no effect on interrupting transmission. Such practices benefit 


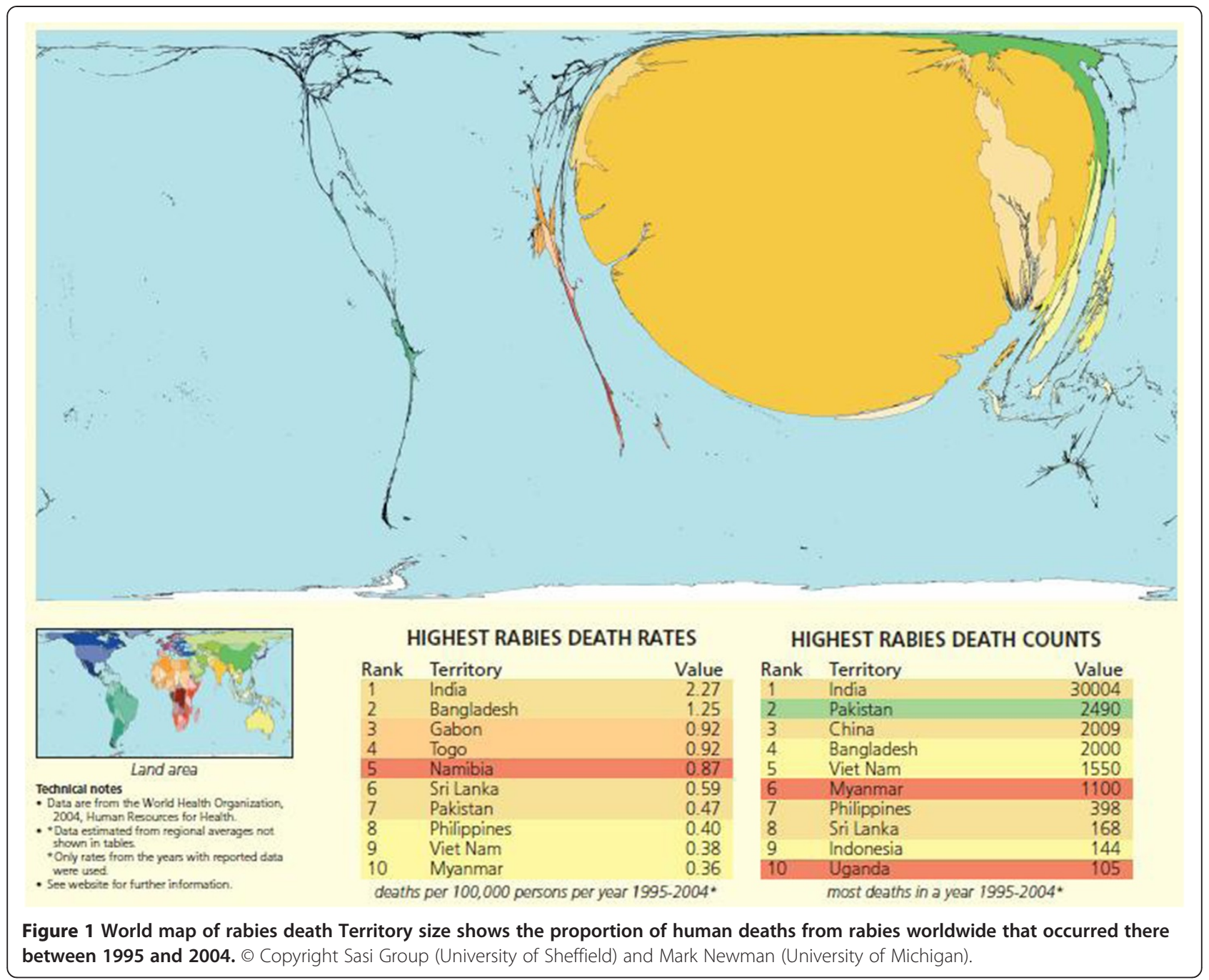

large drug companies but not the poor dwellers, who have to spend the equivalent of several months income on the cost of post exposure prophylaxis. Surveillance in $\operatorname{dogs}$ and in humans reports a fraction of the suspected numbers of cases and there is still a lack of communication between the public health and veterinary sector on the subject. Why is it not attractive to do research on effective control and elimination? Rolling out large-scale campaigns against dog rabies is as complex as systems biology at the subcellular level. Reaching sufficient coverage to interrupt virus transmission requires an in-depth understanding of delivery, availability, accessibility, affordability, adequacy, acceptability and many other effectiveness factors [8-10]. The article by Yin and co-workers shows an appalling situation of research still focussing on the biology of rabies rather than on the community-effectiveness of interventions. This observation is not unique for rabies, but in the case of rabies it appears almost cynical. There is a huge potential for research into the determinants of how dog rabies can be effectively eliminated. For a broad range of zoonoses and neglected tropical diseases, scientists seem to prefer sophisticated molecular analyses over investigating in effective interventions in communities. Why are research funding agencies much less interested into research aiming at effectiveness determinants rather than the biology of pathogens?

\section{Conclusion}

Research should contribute to fill the gap between knowledge and effective action by addressing the social, political, economic and psychological complexity of effective rabies control interventions. This will require that scientists closely collaborate with authorities and communities as partners in a transdisciplinary way $[11,12]$. Interestingly, the study of transmission dynamics during elimination yields new insights into fundamental parameters of pathogen virulence. National governments should recognize that freedom of dog rabies is a public good, for which public funds should be invested without 
delay [10]. Let us move now from the biological understanding to the science of rabies elimination.

\section{Additional file}

Additional file 1: Multilingual abstracts in the six official working languages of the United Nations.

\section{Competing interests}

The author declares that they have no competing interests.

Received: 20 September 2013 Accepted: 27 September 2013

Published: 2 October 2013

\section{References}

1. Zinsstag J: Animal health research. Sci 2007, 315:1193.

2. Yin WW, Dong J, Tu CC, Edwards J, Guo FS, Zhou H, Yu HJ, Vong S:

Challenges and Needs for China to Eliminate Rabies. Inf Dis Poverty 2013,

2. in press.

3. Cleaveland S, Kaare M, Knobel D, Laurenson MK: Canine vaccinationproviding broader benefits for disease control. Vet Microbiol 2006, 117:43-50.

4. Hampson K, Dushoff J, Bingham J, Bruckner G, Ali YH, Dobson A: Synchronous cycles of domestic dog rabies in sub-Saharan Africa and the impact of control efforts. Proc Natl Acad Sci USA 2007, 104:7717-7722.

5. Knobel DL, Cleaveland S, Coleman PG, Fevre EM, Meltzer MI, Miranda ME, Shaw A, Zinsstag J, Meslin FX: Re-evaluating the burden of rabies in Africa and Asia. Bull. World Health Organ 2005, 83:360-368.

6. Zinsstag J, Durr S, Penny MA, Mindekem R, Roth F, Menendez Gonzalez S, Naissengar S, Hattendorf J: Transmission dynamics and economics of rabies control in dogs and humans in an African city. PNAS 2009, 106:14996-15001.

7. Hampson K, Dushoff J, Cleaveland S, Haydon DT, Kaare M, et al: Transmission dynamics and prospects for the elimination of canine rabies. PLoS Biol 2009, 7(3):e1000053. 10.1371/journal.pbio.1000053.

8. Kayali U, Mindekem R, Yemadji N, Vounatsou P, Kaninga Y, Ndoutamia AG, Zinsstag J: Coverage of pilot parenteral vaccination campaign against canine rabies in N'Djamena, Chad. Bull. World Health Organ 2003, 81:739-744.

9. Obrist B, Iteba N, Lengeler C, Makemba A, Mshana C, Nathan R, Alba S, Dillip A, Hetzel MW, Mayumana I, Schulze A, Mshinda H: Access to health care in contexts of livelihood insecurity: a framework for analysis and action. PLoS Med 2007, 4(10):1584-1588.

10. Dürr $S$, Meltzer M, Mindekem R, Zinsstag J: Owner valuation of rabies vaccination in dogs, Chad. Emerg Infect Dis 2008, 14:1650-1652.

11. Hirsch Hadorn G, Hoffmann-Reim H, Biber-klemm S, Grossenbacher W, Joye D, Pohl C, Wiesmann U, Zemp E: Handbook of Transdisciplinary Research. Heidelberg, Germany: Springer; 2008.

12. Charron DF: Ecosystem approaches to health for a global sustainability agenda. Ecohealth 2012, 9:256-266

doi:10.1186/2049-9957-2-22

Cite this article as: Zinsstag: Towards a science of rabies elimination. Infectious Diseases of poverty 2013 2:22

\section{Submit your next manuscript to BioMed Central and take full advantage of:}

- Convenient online submission

- Thorough peer review

- No space constraints or color figure charges

- Immediate publication on acceptance

- Inclusion in PubMed, CAS, Scopus and Google Scholar

- Research which is freely available for redistribution 